\title{
Anatomical Correlates of Sentence Comprehension and Verbal Working Memory in Neurodegenerative Disease
}

\author{
Serena Amici, ${ }^{1,4}$ Simona M. Brambati, ${ }^{1}$ David P. Wilkins, ${ }^{2}$ Jennifer Ogar, ${ }^{2}$ Nina L. Dronkers, ${ }^{2,3}$ Bruce L. Miller, ${ }^{1}$ and \\ Maria Luisa Gorno-Tempini ${ }^{1}$ \\ ${ }^{1}$ Memory and Aging Center, Department of Neurology, University of California, San Francisco, San Francisco, California 94143-1207, ${ }^{2}$ Veterans Affairs \\ Northern California Health Care System, Martinez, California 94553, ${ }^{3}$ University of California, Davis, Davis, California 95616, and ${ }^{4}$ Department of \\ Neurosciences, University of Perugia, 06126 Perugia, Italy
}

This study investigates whether sentence comprehension and nonsyntactic verbal working memory (vWM) are sustained by the same or by different neural systems. Scores in a sentence-picture matching task and in digits backward (DB) were correlated with magnetic resonance imaging voxelwise gray matter volumes using voxel-based morphometry in 58 patients with neurodegenerative diseases. Results showed that overall sentence comprehension scores, regardless of grammatical structure, correlated with gray matter volumes in the left temporoparietal region, whereas DB scores correlated with dorsolateral prefrontal and inferior parietal volumes. Comprehension of multiclausal relative sentences (type 3) significantly correlated with voxels in the dorsal portion of the left inferior and middle frontal gyri. When DB and multiclausal relative sentences were directly compared, they showed overlapping neural substrates in the dorsolateral left frontal region, supporting a single source of vWM for syntactic and nonsyntactic tasks. Within this large area of common involvement, a small portion of pars triangularis showed an independent effect of multiclausal sentences, whereas a region in the middle frontal gyrus showed greater correlation with DB. This study reconciles two opposing views, which hold that sentence comprehension and vWM rely on either the same or different anatomical resources.

Key words: primary progressive aphasia; sentence comprehension; working memory; magnetic resonance imaging; voxel-based morphometry; syntax

\section{Introduction}

Sentence comprehension requires the understanding of words and phrases and their unique relationships. It is widely accepted that verbal working memory (vWM) is necessary for sentence comprehension, but the cognitive and anatomical interdependence of syntactic and $\mathrm{vWM}$ processes are under debate.

The rules of word structure and arrangement are termed "syntax." In English, the most common sentence type follows the basic subject-verb-object ("canonical") word order (e.g., the girl is pushing the boy). Sentences with noncanonical word order, such as passive sentences, do not follow this particular rule (e.g., the girl is being pushed by the boy) and are generally considered to be more complex and difficult to understand. Furthermore, a simple English sentence tends to have one clause, with canonical ordering, and encodes a single proposition. Sentential complexity increases when a sentence has more than one clause, especially when one clause is embedded within the main clause of the sen-

\footnotetext{
Received Nov. 4, 2006; accepted April 9, 2007.

This work was supported by the National Institute of Neurological Diseases and Stroke (R01 NS50915), the National Institute on Aging (P01 AG019724 and P50 AG-03-006), the California Department of Health (DHS 0435516), and the University of California, San Francisco General Clinical Research Center (M01 RR00079). We thank our patients for participating in the study, and their caregivers. We also thank Juliana Baldo for helpful comments on a previous version of this manuscript.

Correspondence should be addressed to Maria Luisa Gorno-Tempini, 350 Parnassus Avenue, San Francisco, CA 94143-1207. E-mail: marilu@memory.ucsf.edu.

DOI:10.1523/JNEUROSCI.1331-07.2007

Copyright $\odot 2007$ Society for Neuroscience $\quad$ 0270-6474/07/276282-09\$15.00/0
}

tence (e.g., the girl who is pushing the boy is happy). Comprehension of passive and multiclausal sentences relies on $\mathrm{vWM}$ resources, because words and phrases need to be held in memory and manipulated to understand who is doing what to whom (Baddeley and Hitch, 1974; Grodzinsky, 2000). Whether there is a specific cognitive or anatomic vWM component dedicated to syntactic processing is unclear. Some authors (Just and Carpenter, 1992) propose that syntactic comprehension depends on general vWM mechanisms, whereas others predict a vWM component dedicated to on-line sentence processing (Caplan and Waters, 1999).

Sentence comprehension is sustained by a large network of perisylvian brain regions (Caplan et al., 1996; Just et al., 1996; Cooke et al., 2006). Within this network, the left inferior frontal cortex is particularly involved in the comprehension of complex sentences (Caramazza and Zurif, 1976; Cooke et al., 2002; Fiebach et al., 2005). However, this region has also been consistently associated with nonsyntactic vWM tasks (Canavan et al., 1989; Paulesu et al., 1993; D’Esposito et al., 1999). Only a few functional neuroimaging studies have investigated the nonlinguistic vWM contribution to sentence comprehension, and the results are still debated (Bottini et al., 1994; Stowe et al., 1998; Friederici et al., 2000).

Although it is accepted that vWM is necessary for the comprehension of complex sentences, the specificity of this process for syntax is unclear. The aim of the present study was to compare the 
Table 1. Demographics and neuropsychological data

\begin{tabular}{|c|c|c|c|c|c|}
\hline & All patients [mean (SD)] & PNFA $[$ mean (SD)] & Semantic dementia [mean (SD)] & $\mathrm{LPA}[$ mean $(\mathrm{SD})]$ & 0ther $[$ mean $(S D)]$ \\
\hline \multicolumn{6}{|l|}{ Demographic } \\
\hline Age & $64.7(8.8)$ & $65.7(8.4)$ & $65.2(7.3)$ & $66.4(9.8)$ & $60.3(9.8)$ \\
\hline Gender (M/F) & $29 / 29$ & $6 / 13$ & $10 / 6$ & $7 / 5$ & $6 / 5$ \\
\hline $\operatorname{MMSE}(\max =30)$ & $24.2(4.8)$ & $25.4(4.8)$ & $23.9(4.48)$ & $21.8(5.30)$ & $24.8(5.1)$ \\
\hline \multicolumn{6}{|l|}{ Neuropsychological screening } \\
\hline WAB fluency (10) & $8.3(2.2)$ & $7.6(3.0)$ & $8.8(1.4)$ & $8.2(1.5)$ & $9.0(1.8)$ \\
\hline MSE apraxia of speech (7) & $1.2(2.0)$ & $2.7(2.6)^{c, d}$ & $0(0)$ & $1.4(1.6)$ & $0.4(1.2)$ \\
\hline WAB word recognition total (60) & $57.1(6.1)$ & $59.4(1.2)$ & $52.2(9.6)^{a, b, d}$ & $58.8(1.0)$ & \\
\hline Abbreviated BNT (15) & $9.0(4.8)$ & $11.9(2.5)$ & $3.7(3.9)^{a, d}$ & $9.3(3.0)$ & $9.0(1.8)$ \\
\hline WAB repetition (100) & $87.0(14.0)$ & $86.7(12.3)$ & $91.3(8.0)$ & $78.0(18.8)^{e}$ & $91.9(14.6)$ \\
\hline Phonemic word generation & $7.0(4.6)$ & $5.3(3.3)$ & $5.8(4.5)$ & $8.7(5.6)$ & $9.4(3.7)$ \\
\hline Semantic word generation & $8.4(4.9)$ & $11.6(4.8)$ & $4.6(3.0)^{a, b, d}$ & $7.6(3.7)$ & $11.0(5.0)$ \\
\hline Modified Rey-0 delay (17) & $7.7(4.4)$ & $9.4(4.4)$ & $8.5(4.2)$ & $5.7(4.1)$ & $7.0(4.6)$ \\
\hline CVLT-MS 4-trails correct total (36) & $16.21(8.1)$ & $21.4(7.9)^{b, c}$ & $11.9(5.5)$ & $12.5(6.2)$ & $18.1(9.0)$ \\
\hline CVLT-MS 10' free recall (9) & $3.0(3.2)$ & $5.7(3.3)^{b, c}$ & $1.2(2.1)$ & $1.4(1.6)$ & $3.0(2.6)$ \\
\hline Modified Rey-0 copy (17) & $13.9(4.0)$ & $12.9(5.2)$ & $16.1(0.9)$ & $13.4(2.5)$ & $12.7(5.2)$ \\
\hline \multicolumn{6}{|l|}{ Verbal working memory } \\
\hline Digits span backward & $3.7(1.6)$ & $3.10(1.32)$ & $4.18(1.16)$ & $3.25(1.12)$ & $4.27(2.41)$ \\
\hline \multicolumn{6}{|l|}{ Sentence comprehension } \\
\hline CYCLE-R total score (55) & $47.7(7.5)$ & $48.3(6.4)$ & $49.4(7.0)$ & $44.0(9.3)$ & $48.4(7.7)$ \\
\hline Type 1 (simple sentences accuracy, \%) & $97.6(4.6)$ & $98.6(2.8)$ & $97.1(5.4)$ & $95.6(6.6)$ & $98.8(2.7)$ \\
\hline Type 2 (non-canonical monopropositional, \%) & $83.6(17.1)$ & $86.6(13.2)$ & $86.2(15.9)$ & $73.7(22.2)$ & $85.4(16.9)$ \\
\hline Type 3 (multiclausal relatives, \%) & $81.8(21.4)$ & $80.8(21.2)$ & $88.1(19.3)$ & $74.5(24.5)$ & $82.2(21.4)$ \\
\hline \multicolumn{6}{|l|}{$a_{p}<0.05$ versus PNFA. } \\
\hline \multicolumn{6}{|l|}{${ }^{b} p<0.05$ versus $L P A$} \\
\hline \multicolumn{6}{|l|}{${ }^{\prime} p<0.05$ versus semantic dementia. } \\
\hline${ }^{d} p<0.05$ versus other dementias. & & & & & \\
\hline
\end{tabular}

anatomical substrates of nonsyntactic vWM and sentence comprehension for different types of deviation from the basic monoclausal, monopropositional canonical structure. We applied voxel-based morphometry (VBM) to correlate digits backward (DB) and the Curtiss-Yamada Comprehensive Language Evaluation-Receptive Test (CYCLE-R) (S. Curtiss, J. Yamada, unpublished test) scores with voxelwise gray matter volumes in 58 patients with neurodegenerative diseases. We used neurodegenerative disease as a model because it provides a wide distribution of neuropsychological scores and gray matter loss. We hypothesized that sentence comprehension will correlate with volumes in the left posterior temporal/inferior parietal region (Just et al., 1996; Keller et al., 2003), whereas vWM and comprehension of complex sentences will involve the left middle and inferior frontal gyri (Keller et al., 2001; Friederici et al., 2003).

\section{Materials and Methods}

\section{Subjects}

Fifty-eight native English-speaking, right-handed patients with a diagnosis of neurodegenerative disease participated in this study. There was a 1:1 male-to-female ratio and the mean age was $64.7 \pm 8.8$ years (Table 1 ). All patients were recruited at the Memory and Aging Center at the University of California, San Francisco. Inclusion criteria were the presence of prominent speech or language symptoms at each patient's first evaluation and the availability of a magnetic resonance imaging (MRI) scan within 6 months of the clinical evaluation.

A detailed medical history and a comprehensive neurological and neuropsychological evaluation (Kramer et al., 2003) were used by a team of clinicians to formulate a consensus diagnosis for each patient, according to the currently published criteria (McKhann et al., 1984; Mesulam, 1987; McKeith et al., 1996; Litvan et al., 1997; Neary et al., 1998). Fortyseven patients met criteria for primary progressive aphasia [PPA; 19 patients with progressive nonfluent aphasia, 16 patients with semantic dementia, and 12 patients with logopenic progressive aphasia (LPA)]. The remaining 11 patients, although complaining of language symp- toms, did not meet PPA criteria and were diagnosed with frontotemporal dementia $(n=3)$, Alzheimer's disease $(n=3)$, corticobasal syndrome $(\mathrm{CBS}) /$ progressive supranuclear palsy (PSP; $n=4$ ), and Lewy body disease (DLB; $n=3$ ). Including patients with different clinical syndromes augmented the anatomical and behavioral variability of the sample and increased the validity of our statistical model. Diagnosis was based on clinical features, and we did not attempt to predict specific histopathological changes postmortem. CBS, PSP, and DLB were diagnosed using current clinical criteria (Litvan et al., 1996; Boeve et al., 2003; McKeith et al., 2005). The large number of patients with PPA in our sample can be explained by the focus of our center on atypical dementias, and by our effort to include patients presenting with different language syndromes. Each subject or their caregiver signed informed consent documents approved by the University of California, San Francisco Committee on Human Research.

\section{Cognitive tasks}

Sentence comprehension. As part of a comprehensive language evaluation (for details, see Gorno-Tempini et al., 2004), subjects performed an offline sentence picture-matching task, the CYCLE-R (Curtiss, Yamada, unpublished test). Eleven CYCLE-R subtests were used, as reported previously in a study of patients with aphasia caused by vascular lesions (Dronkers et al., 2004). Each subtest focuses on a distinct sentence structure and contains five sentences, differing in the content items used (i.e., verbs and/or noun phrases used). All sentences are complete declarative (with animate subjects), which describe a state of affairs that can be depicted through line drawings. All sentences are semantically plausible and reversible (except declarative sentences) (for more information, see Table 2). Participants listen to a sentence and match their interpretation with one picture from an array of three or four line drawings. The examiner was instructed to repeat the sentence a second time if the patient had difficulties in choosing a picture.

The eleven subtests can be classified into three types on both morphosyntactic and semantic grounds: type 1 contains basic sentence structures, whereas types 2 and 3 deviate from the basic structures (Table 2).

"Type 1" or "simple sentences" (monopropositional canonical sen- 
Table 2. CYCLE-R characteristics

\begin{tabular}{|c|c|c|c|c|}
\hline $\begin{array}{l}\text { Subtest (type) and example } \\
\text { prompt sentence }\end{array}$ & Target & Foil 1 & Foil 2 & Foil 3 \\
\hline $\begin{array}{l}\text { (1) Simple declarative 2.8: } \\
\text { "The boy is jumping" } \\
\text { (1) Possession 3.10: "The }\end{array}$ & $\begin{array}{l}\text { Person } X \text { doing single participant } \\
\text { action } A\end{array}$ & $\begin{array}{l}\text { Person } Y \text { doing single partici- } \\
\text { pant action A } \\
\text { Possessor X "has" thing Q (or }\end{array}$ & $\begin{array}{l}\text { Person } X \text { doing single participant } \\
\text { action B }\end{array}$ & $\mathrm{N} / \mathrm{A}$ \\
\hline $\begin{array}{l}\text { clown has a balloon" } \\
\text { (1) Active voice 4.2: "The girl is }\end{array}$ & Possessor $X$ has thing $P$ & $\begin{array}{l}\text { nothing) } \\
\text { Person } Y \text { doing action A to }\end{array}$ & $\begin{array}{l}\text { Possessor } Y \text { "has" thing } P \\
\text { Animate } Z \text { doing action } A \text { to person }\end{array}$ & N/A \\
\hline pulling the boy" & Person $X$ doing action $A$ to person $Y$ & person X [reverse ] & Y & Persons $X$ and $Y$ doing \\
\hline $\begin{array}{l}\text { (2) Agentless passive } 4.11 \text { : } \\
\text { "The boy is being pushed" } \\
\text { (2) Agentive passive } 5.6: \text { "The }\end{array}$ & Person $Y$ doing action $A$ to person $X$ & $\begin{array}{l}\text { Person } \mathrm{X} \text { doing action A to } \\
\text { person } \mathrm{Y} \text { [reverse] }\end{array}$ & $\begin{array}{l}\text { Person } \mathrm{X} \text { doing action } \mathrm{A} \text { to inani- } \\
\text { mate I }\end{array}$ & $\mathrm{N} / \mathrm{A}$ \\
\hline $\begin{array}{l}\text { boy is being pushed by the } \\
\text { girl" } \\
\text { (2) Object clefting 8.1:" It's the }\end{array}$ & Person $Y$ doing action $A$ to person $X$ & $\begin{array}{l}\text { Person } X \text { doing action A to } \\
\text { person } Y \text { [reverse }] \\
\text { Person } Y \text { doing action A to }\end{array}$ & Person $Y$ doing action $A$ to person $Z$ & Person $Z$ doing action $A$ to person $X$ \\
\hline $\begin{array}{l}\text { clown that the girl chases" } \\
\text { (2) Negative passive 9.2: "The }\end{array}$ & Person $X$ doing action $A$ to person $Y$ & person $X$ [reverse $]$ & Person $X$ doing action $A$ to person $Z$ & Person $Y$ doing action $A$ to person $Z$ \\
\hline $\begin{array}{l}\text { clown is not being followed by } \\
\text { the girl" }\end{array}$ & $\begin{array}{l}\text { Animate } X \text { doing action } A \text { to animate } \\
Y\end{array}$ & $\begin{array}{l}\text { Animate } Y \text { doing action } A \text { to } \\
\text { animate } X \text { [reverse] } \\
\text { Person } X \text { with visible charac- }\end{array}$ & $\begin{array}{l}\text { Animate } Z \text { doing action } A \text { to animate } \\
\quad X\end{array}$ & $\mathrm{~N} / \mathrm{A}$ \\
\hline $\begin{array}{l}\text { (3) Double embedding 4.3: } \\
\text { "The clown that is big has the } \\
\text { balloon that is blue" }\end{array}$ & $\begin{array}{l}\text { Person X with visible characteristic C } \\
\text { "has"/ acts on Y with visible } \\
\text { characteristic D }\end{array}$ & $\begin{array}{l}\text { teristic "not } C^{\prime \prime} \text { "has"/ acts } \\
\text { on Y with visible character- } \\
\text { istic D } \\
\text { Person Y with visible charac- }\end{array}$ & $\begin{array}{l}\text { Person X with visible characteristic C } \\
\text { "has"/ acts on Y with visible } \\
\text { characteristic "not D" }\end{array}$ & $\begin{array}{l}\text { Person X with visible characteristic } \\
\text { "not C" "has"/ acts on Y with } \\
\text { visible characteristic "not D" }\end{array}$ \\
\hline $\begin{array}{l}\text { (3) Subject relatives 7.7: "The } \\
\text { girl who is pushing the boy is } \\
\text { happy" }\end{array}$ & $\begin{array}{l}\text { Person } \mathrm{X} \text { with visible characteristic } \mathrm{C} \\
\text { doing action } \mathrm{A} \text { to person } \mathrm{Y} \text { with } \\
\text { visible characteristic "not C" }\end{array}$ & $\begin{array}{l}\text { teristic C doing action A to } \\
\text { person } \mathrm{X} \text { with visible char- } \\
\text { acteristic" not C" } \\
\text { Person Y with visible charac- }\end{array}$ & $\begin{array}{l}\text { Person } X \text { with visible characteristic } \\
\text { "not C" doing action A to person } \\
\text { Y with visible characteristic C }\end{array}$ & $\begin{array}{l}\text { Person Y with visible characteristic } \\
\text { "not C" doing action A to person } \\
\text { X with visible characteristic "C" }\end{array}$ \\
\hline $\begin{array}{l}\text { (3) Object relative clauses } \\
\text { 8.2: "The girl is chasing the } \\
\text { clown who is big" } \\
\text { (3) Object relative with rela- }\end{array}$ & $\begin{array}{l}\text { Person } \mathrm{X} \text { with visible characteristic } \mathrm{C} \\
\text { doing action A to person } \mathrm{Y} \text { with } \\
\text { visible characteristic "not C" }\end{array}$ & 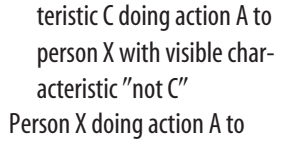 & 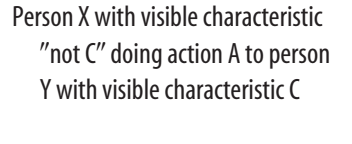 & $\begin{array}{l}\text { Person Y with visible characteristic } \\
\text { "not C" doing action A to person } \\
\text { X with visible characteristic "C" }\end{array}$ \\
\hline $\begin{array}{l}\text { tivized object 9.3: "The girl } \\
\text { is kissing the boy that the } \\
\text { clown is hugging" }\end{array}$ & $\begin{array}{l}\text { Person } X \text { doing action } A \text { to person } Y \text {, } \\
\text { at same time person } Z \text { doing } \\
\text { action } B \text { to person } Y\end{array}$ & $\begin{array}{l}\text { person } Y \text {, at same time } \\
\text { person } Y \text { doing action } B \text { to } \\
\text { person } Z\end{array}$ & $\begin{array}{l}\text { Person } Y \text { doing action } A \text { to person } X \text {, } \\
\text { at same time person } Z \text { doing } \\
\text { action } B \text { to person } Y\end{array}$ & $\begin{array}{l}\text { Person } X \text { doing action } A \text { to person } Z \text {, } \\
\text { at same time person } Y \text { doing } \\
\text { action } B \text { to person } Z\end{array}$ \\
\hline
\end{tabular}

On hearing a sentence, the subject was meant to select a target picture from among the foils. The set of pictures has the above-mentioned feature contrasts. In parentheses and bold, our grouping of the subtests; in bold, the name of the subtest according to Curtiss and Yamada (unpublished test); in italics and underlined, the original coding numbers of the subtests; in italics and quoted, an example from the subtest. N/A, Not applicable.

tences) are sentences in which a single proposition is encoded. Thematic structure and word order have a canonical alignment (simple declaratives, possession, and active voice word order).

"Type 2" or "word order sentences" (monopropositional sentences with changes in thematic structure) are those in which a single proposition is encoded in the presence of a change in thematic structure that gives discourse prominence to the underlying object of the sentence (passive voice word order I, passive voice word order II, object clefting, and negative passives).

"Type 3" or "multiclausal relatives" (multiclausal sentences with embedded relative clauses) have multiclausal structures in which a relative clause is embedded within the subject and/or object of the sentence (double embedding, subject relatives ending in noun-verb, object-subjectrelative clauses, and object-object relatives with relativized object structures) (Table 2).

$v W M$. vWM was investigated with the WAIS-III (Wechsler Adult Intelligence Scale, third edition) DB (Wechsler, 1997). The subject was asked to repeat a progressively increasing number of random digits in reverse order, starting from two digits. The score is equal to the number of digits correctly repeated in reverse order.

\section{Statistical analysis of cognitive data}

One-way ANOVA for parametric data and Kruskal-Wallis test for nonparametric data were used to detect differences in cognitive data across diagnostic categories. The Wilcoxon signed-ranked test was used to detect differences in accuracy scores between the three types of sentence. Accuracy of response for the total CYCLE-R and for each of the three sentence types was correlated with DB span scores using Spearman's test.
Statistical analyses were performed with SPSS software (version 10.0.5 for Windows; SPSS, Chicago, IL).

\section{MRI study}

MRI scanning. MRI scans were obtained on a 1.5T Magnetom VISION system (Siemens, Iselin, NJ). A volumetric magnetization-prepared rapid gradient-echo sequence (repetition time, $10 \mathrm{~ms}$; echo time, $4 \mathrm{~ms}$; inversion time, $300 \mathrm{~ms}$ ) was used to obtain T1-weighted images of the entire brain $\left(15^{\circ}\right.$ flip angle; coronal orientation perpendicular to the double spin-echo sequence; $1.0 \times 1.0 \mathrm{~mm}^{2}$ in-plane resolution; $1.5 \mathrm{~mm}$ slab thickness).

$V B M$. VBM was used to correlate performance in sentence comprehension and vWM with voxelwise gray matter volumes. VBM comprised two steps: spatial preprocessing (normalization, segmentation, Jacobian modulation, and smoothing) and statistical analysis. Both steps were implemented using the Statistical Parametric Mapping (SPM2) software package (Wellcome Department of Imaging Neuroscience, London; http://www.fil.ion.ucl.ac.uk/spm) running on Matlab 6.5.1 (MathWorks, Natick, MA).

MRI images were spatially preprocessed using the "optimized" method for spatial normalization of gray matter (Good et al., 2001). Age-matched templates and a priori images were created by averaging 30 age-matched normal control scans that had been normalized and segmented in the Montreal Neurological Institute stereotaxic space. A twostep segmentation procedure was applied to each scan included in this analysis. First, T1-weighted images were segmented in native space and then normalized to the gray matter template. The parameters obtained from the gray-matter normalization were then applied to the original $\mathrm{T} 1$ 
images. Finally, the normalized images were segmented again into gray matter, white matter, and CSF. Gray matter voxel values were multiplied by the Jacobian determinants derived from the spatial normalization step (Jacobian modulation) to preserve the initial volumes. Modulated gray matter images were then spatially smoothed with a $12 \mathrm{~mm}$ full-width at half-maximum isotropic Gaussian kernel.

The VBM technique has known limitations, such as limited spatial resolution and possible registration errors (Ashburner and Friston, 2001; Bookstein, 2001). VBM has been validated to study group differences in patients with neurodegenerative disease (Good et al., 2002) and has been applied successfully to correlate voxelwise brain volumes with behavioral performance (Rosen et al., 2005; Brambati et al., 2006).

Statistical analyses used the "covariate-only" model in SPM2, and all subjects were entered as a single group. Cognitive scores in the tests of interest were entered as independent covariates. Total gray matter, age, and gender were used as nuisance variables. Mini-mental state examination (MMSE) was not included as a nuisance variable because MMSE scores are influenced by language and vWM abilities.

First, to identify the whole network of brain regions associated with each task, we investigated the effect of each variable separately (main effect). Four design matrices were constructed in which only one of these four covariates was entered: CYCLE-R total accuracy, type 2 (word order sentences) accuracy, type 3 (mutipropositional relatives) accuracy, and DB scores. Type 1 sentences were not considered separately because accurate scores in these subtests could be achieved using pragmatic strategies and single word comprehension.

Additional analyses were performed to identify areas that correlated with both comprehension of complex sentences, such as type 2 and 3, vWM (common effects), and regions that showed independent effects of one covariate or the other (independent effects). The same design matrix, including two independent covariates of interest (sentence comprehension and vWM scores) was used for both purposes (for illustration of the design matrix, see Fig. 2). Scores in type 1 canonical sentences were entered as an additional nuisance, together with age, gender, and total gray matter volume, to control for word and simple sentence comprehension skills. A conjunction analysis of the $(+10)$ and $(0+1) t$ contrasts was used to identify voxels where there was a positive correlation between gray matter volumes and both sentence comprehension and vWM. The conjunction results were inclusively masked with each individual contrast to assure that the effect was present at each contrast (Friston et al., 1999, 2005). The two $t$ contrasts $(+10)$ and $(0+1)$ were used to identify regions that showed independent positive correlation between gray matter volume and comprehension of complex sentences or vWM scores, respectively. These two contrasts identify only regions in which one of the two covariates showed an independent effect.

Based on previous work, we restricted our analysis to a left hemisphere network of regions that have been previously implicated in sentence comprehension and vMW (Fiez et al., 1996; Just et al., 1996; Binder et al., 1997; D’Esposito et al., 1999; Friederici et al., 2003). This region of interest (ROI) included the left inferior and middle frontal gyri, the left superior and middle temporal gyri, and the left inferior parietal lobule. The ROI was drawn using the Anatomical Automatic Labeling brain atlas (Tzourio-Mazoyer et al., 2002) and was applied to the SPM dataset Wake Forest University Pick atlas (Maldjian et al., 2003) (http://www.ansir. wfubmc.edu/download.htm).

Within this ROI, we accepted a level of significance of $p<0.05$ corrected for multiple comparisons using the false discovery rate (FDR) (Genovese et al., 2002) correction procedure in SPM for main effects, whereas we used the less stringent threshold of $p<0.001$ uncorrected for the independent effects.

To better understand the effect of each variable in the regression model and to test for violations of the assumptions of linear regression, the analyses performed in SPM were duplicated in SPSS for all peak voxels. We used raw values from the smoothed gray matter images as dependent variables and the same independent variables (covariates) that were entered into the SPM design matrix. The linear form of the relationship of the dependent variable with each independent variable and homoscedasticity of the residuals was examined by plotting the residuals against the independent variables and the predicted values, with superimposed zero- lines and Lowess curves. Normality of the residuals was inspected with normal q-q plots. Multicollinearity was evaluated with the value inflation factor and comparison of the $\beta$ coefficients to the corresponding zeroorder correlation coefficients (Cohen, 1988).

\section{Results}

\section{Behavioral data}

Demographic information and performance on neuropsychological measures for each patient group is presented in Table 1. The diagnostic groups did not differ with regard to gender, age at evaluation, or MMSE score. All groups had the lowest scores on understanding noncanonical structures (Table 1) [type 2 (word order) vs type 1 (simple sentences): $Z=-3.5, p=0.01$; type 3 (multiclausal relatives) vs type 1 (simple sentences): $Z=-3.1$, $p=0.01]$, but no significant difference was detected between the two sentence types with noncanonical structures (type 2 vs type $3: Z=-1.6, p=0.1$ ). DB abilities correlated significantly with CYCLE-R total accuracy score (Spearman's $\rho, 0.6$; $p<$ 0.001 ) and type 2 (Spearman's $\rho, 0.5 ; p<0.001$ ) and type 3 (Spearman's $\rho, 0.6 ; p<0.001$ ) accuracy scores. Accuracies of type 2 and of type 3 sentences were also highly correlated (Spearman's $\rho, 0.7 ; p<0.001$ ).

\section{Imaging data}

The results of each analysis listed in Materials and Methods are reported separately.

\section{Main effect of CYCLE-R}

The CYCLE-R total score correlated with the left posterior superior temporal gyrus [Brodmann's area (BA) 22/41; cluster size, 2066 voxels; $x, y, z$ coordinates (in $\mathrm{mm}$ ): $-46,-38,15$, respectively; $Z=4.2 ; p_{\mathrm{FDR}}=0.03$; cluster size, $326 ; x, y, z$ coordinates: $-64,-53,16$, respectively; $\left.Z=3.5 ; p_{\mathrm{FDR}}=0.03\right]$, middle temporal (BA 39; within the same 2066 voxel cluster as above; $x, y, z$ coordinates: $-46,-54,10$, respectively; $Z=3.9 ; p_{\mathrm{FDR}}=0.03$; cluster size, $410 ; x, y, z$ coordinates: $-54,69,21$, respectively; $Z=$ $3.5 ; p_{\mathrm{FDR}}=0.03$ ), and inferior parietal lobule (BA 40; within the same 2066 voxel cluster as above; $x, y, z$ coordinates: $-55,-55$, 47 , respectively; $Z=3.9 ; p_{\mathrm{FDR}}=0.03$; cluster size, $637 ; x, y, z$ coordinates: $-33,-59,50$, respectively; $Z=3.6$; $p_{\mathrm{FDR}}=0.03$ ] (Fig. 1a).

\section{Main effect of type 2 (word order sentences)}

Performance on type 2 sentences showed only a trend of correlation with the left middle frontal gyrus (BA 9; cluster size, 268; $x, y$, $z$ coordinates: $-38,7,63$, respectively; $\left.Z=4.1 ; p_{\mathrm{FDR}}=0.09\right)(\mathrm{BA}$ 46 ; cluster size, $1.360 ; x, y, z$ coordinates: $-45,45,14$, respectively; $Z=4.0 ; p_{\mathrm{FDR}}=0.09$ ) and left inferior frontal gyri (within the same cluster as above; BA $45 ; x, y, z$ coordinates: $-38,45,8$, respetively; $Z=3.7 ; p_{\mathrm{FDR}}=0.09$ ). These data are not reported in a table form because they did not reach corrected significance.

\section{Main effect of type 3 sentences (multiclausal relatives)}

Performance on type 3 sentences was significantly correlated with gray matter volumes in the left middle, inferior frontal (pars triangularis), and transverse temporal gyri $\left(p_{\mathrm{FDR}}<0.05\right.$, corrected) (Fig. 1c, Table 3 ).

\section{Main effect of $v W M$}

DB scores significantly correlated with volumes in a large region centered on the left dorsolateral prefrontal cortex and inferior parietal lobule (Fig. 1b, Table 3). The right dorsolateral prefrontal cortex was the only other region that correlated significantly with DB scores when an exploratory analysis at whole brain level was performed. 
Common effect of type 3 sentences and $v W M$

The conjunction of type 3 accuracy and DB scores showed a large cluster of gray matter reduction that included the left inferior frontal sulcus and gyrus (pars triangularis; BA 45), and extended anteriorly and superiorly to the middle frontal gyrus (BA 46/9). A separate, smaller cluster was located in the upper portion of the left middle frontal gyrus (BA 6/8) (Fig. 2a, Table 3).

Independent effect of type 3 sentences versus $v W M$

When compared with DB, type 3 sentences showed an independent effect in the left inferior frontal sulcus and gyrus (pars triangularis) (Fig. 2b, red; Table 3 ).

Independent effect of $v W M$ versus type 3 sentences

DB scores correlated significantly with the left middle frontal, inferior frontal, and inferior parietal areas (Fig. $2 b$, green; Table 3 ).

Common and independent effects of type 2 sentences

Type 2 word order sentences did not show a significant main effect, indicating that they did not reliably correlate with any brain region. They showed only a trend in regions similar to multiclausal relatives. Nevertheless, for completeness, we conducted three exploratory analyses to investigate whether type 2 sentences showed any differential effect when compared with type 3 and DB. As expected by the main effect analysis, type 2 sentences (word order) did not show an independent effect when compared with multiclausal relatives (type 3 ). However, type 3 did show a greater effect in the left inferior frontal (BA 45; cluster size 51; $x, y, z$ coordinates: $-41,-37,19$, respectively; $Z=$ 3.2; $p_{\mathrm{FDR}}=0.2$ ) and middle frontal gyri (BA 46; cluster size 16; $x, y, z$ coordinates: $-31,36,28$, respectively; $Z=3.1 ; p_{\mathrm{FDR}}=$

0.2 ). Furthermore, when compared with type 2, DB showed an independent effect in the same region as when it was compared with type 3 (Table 3 ). Finally, when all three variables were entered as three separate covariates into the same statistical model, DB showed the same independent effect as when compared with type 3. However, the effect of type 3 sentences did not reach significance because of its strong correlation with type 2 sentences.

\section{SPSS general linear model}

The duplication of the imaging analyses in SPSS showed that the assumptions of the general linear model were fulfilled in each case, in particular multicollinearity was excluded because the variance inflation factor was $<1.8$ (Cohen, 1988).

\section{Post hoc analyses}

Two post hoc analyses were conducted to investigate the effects of two possible confounds in the study: length difference between sentence types and diagnosis effects. uncorrected.

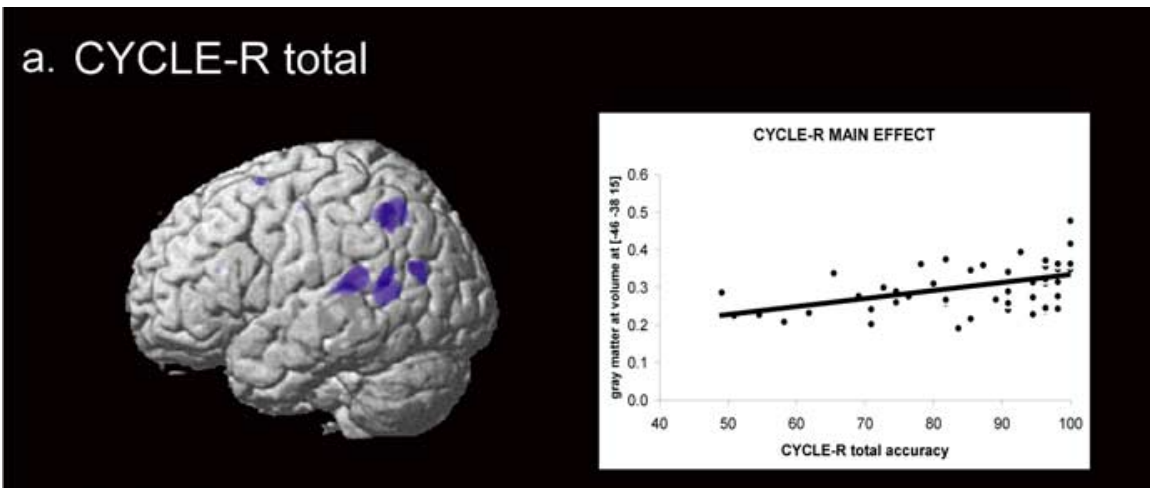

b. Digits backward
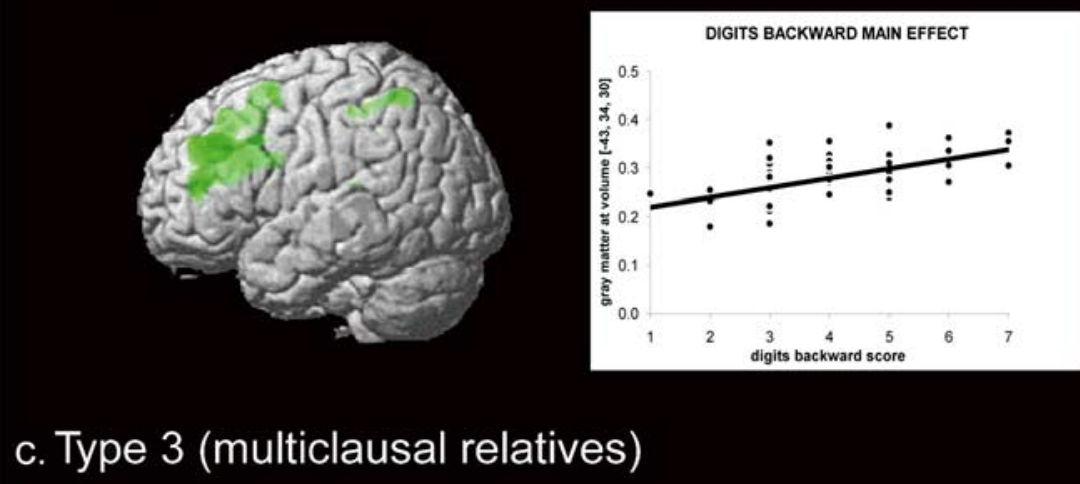

Figure 1. $\quad \boldsymbol{a}$, Main effects of total CYCLE-Raccuracy (blue). $\boldsymbol{b}, \mathrm{DB}$ (green) scores. c, Type 3 sentences (multiclausal relatives; red). The plots show the relationship between gray matter volumes in arbitrary units ( $y$-axis) and the task scores in the $x$-axis for each analysis; in particular, the gray matter volumes represent the highest peak of each contrast. Results are superimposed on the three-dimensional rendering of the Montreal Neurological Institute standard brain and displayed at a threshold of $p<0.001$,

\section{Length effect}

The mean number of words for type 2 was $7.7( \pm 1.3)$; the mean number of words was $10.1( \pm 1.3)$ for type 3 . This difference could explain why type 2 did not correlate significantly with left frontal regions whereas type $3 \mathrm{did}$. To investigate this question, we eliminated from type 3 the subject-relative sentences (4.3) so that the length difference between type 2 and 3 was no longer significant $(p=0.2)$. The main effect of type 3 and the relationship of type 3 to DB remained in the left middle and inferior frontal gyrus and was still significant after multiple comparisons $\left(x, y, z\right.$ coordinates: $-37,6,62$, respectively; $p_{\mathrm{FDR}}<0.05$, corrected).

\section{Diagnosis effect}

Our patient groups comprised patients who either met criteria for different variants of PPA or for other neurodegenerative disorders with prominent speech or language symptoms. This guaranteed that the atrophy included most regions in the left hemi- 
Table 3. VBM results

\begin{tabular}{|c|c|c|c|c|c|c|c|c|c|c|c|c|c|}
\hline Brain regions & $\mathrm{BA}$ & $\mathrm{k}$ & $x$ & $y$ & $z$ & $Z$ & $p_{\mathrm{FDR}}$ & $Z$ & $p_{\mathrm{FDR}}$ & $\beta$ & $Z$ & $p_{\mathrm{FDR}}$ & $\bar{\beta}$ \\
\hline & \multicolumn{7}{|c|}{ Common effect } & \multicolumn{3}{|l|}{ DB } & \multicolumn{3}{|c|}{ Type 3} \\
\hline \multirow[t]{3}{*}{ L inferior frontal gyrus/sulcus pars triangularis } & 45 & 2601 & -41 & 34 & 20 & 4.5 & $<0.01$ & 4.2 & $<0.01$ & 0.5 & 4.3 & $<0.01$ & 0.6 \\
\hline & & & -39 & 44 & 8 & 4.2 & $<0.01$ & 3.2 & $<0.01$ & 0.4 & 4.3 & $<0.01$ & 0.6 \\
\hline & & & -40 & 40 & 12 & 3.9 & $<0.01$ & 3.5 & $<0.01$ & 0.5 & 3.6 & $<0.01$ & 0.6 \\
\hline \multirow[t]{2}{*}{ L middle frontal gyrus } & $46 / 9$ & & -37 & 41 & 22 & 4.0 & $<0.01$ & 4.1 & $<0.01$ & 0.5 & 4.1 & $<0.01$ & 0.5 \\
\hline & & & -29 & 36 & 35 & 3.4 & $<0.01$ & 3.9 & $<0.01$ & 0.5 & 3.8 & $<0.01$ & 0.5 \\
\hline \multirow[t]{2}{*}{ L middle frontal gyrus } & $6 / 8$ & 182 & -39 & 7 & 61 & 4.0 & $<0.01$ & 3.3 & $<0.01$ & 0.4 & 4.1 & $<0.01$ & 0.5 \\
\hline & \multicolumn{12}{|c|}{ Independent effect type 3 versus DB } & \\
\hline \multirow[t]{2}{*}{ L inferior frontal gyrus/sulcus } & 45 & 293 & -34 & 39 & 6 & 3.5 & 0.3 & $2.5^{*}$ & 0.05 & 0.3 & 3.8 & $<0.01$ & 0.5 \\
\hline & \multicolumn{12}{|c|}{ Independent effect DB versus type 3} & \\
\hline L inferior frontal gyrus & 45 & 261 & -52 & 45 & 13 & 3.7 & 0.09 & 4.1 & $<0.01$ & 0.5 & $1.7^{*}$ & 0.1 & \\
\hline L middle frontal gyrus & $45 / 46$ & 1077 & -45 & 32 & 34 & 3.7 & 0.09 & 4.4 & $<0.01$ & 0.5 & $2.2^{*}$ & 0.1 & 0.3 \\
\hline L inferior parietal lobule & 40 & 224 & -43 & -54 & 58 & 3.5 & 0.09 & 3.7 & 0.2 & 0.4 & $2.0^{*}$ & 0.1 & 0.3 \\
\hline
\end{tabular}

Common and independent effects of DB and multiclausal relatives. The second and third columns report the single effect of DB and type 3 sentences in analog regions. Cluster sizes are reported at $p<0.001$, uncorrected. $k$, Cluster size; $L$, left.

${ }^{*} p>0.001$, uncorrected.

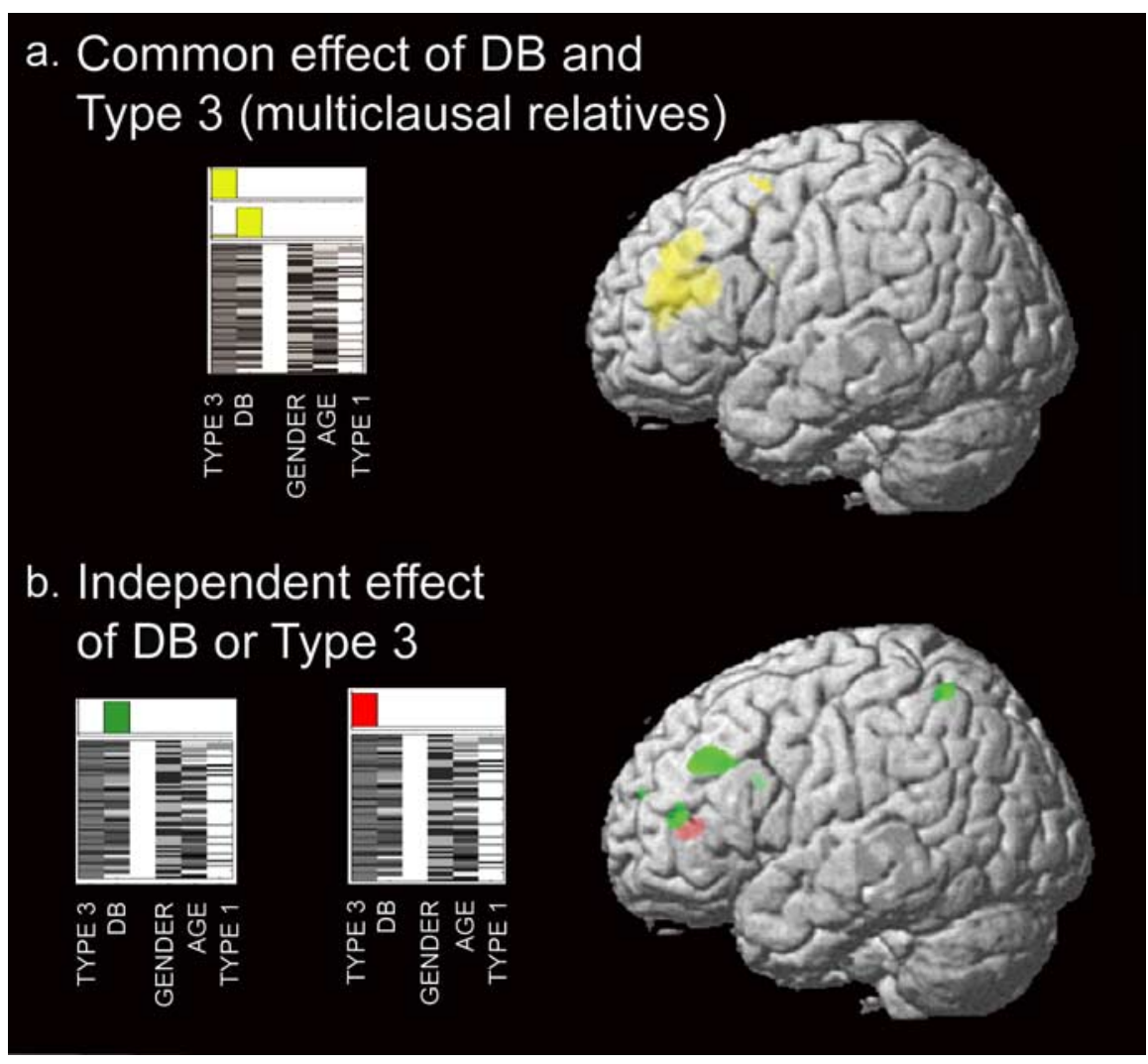

Figure 2. $\quad \boldsymbol{a}$, Conjunction of type 3 sentences and $\mathrm{DB}$ (yellow) showing regions that correlate with both variables. $\boldsymbol{b}$, Independent effect of accuracy for type 3 (red) and DB (green), indicating regions that show correlation with each variable. The design matrix illustrates covariates of interest and confounding variables. Results are superimposed on the three-dimensional rendering of the Montreal Neurological Institute standard brain and displayed at a threshold of $p<0.001$, uncorrected.

rected level of significance for $\mathrm{DB}$ and type 3 ( $p_{\mathrm{FDR}}<0.05$, corrected). The posterior temporal effect for the total CYCLE-R score was also still present but at a lower level of significance $(p<0.001$, uncorrected).

\section{Discussion}

The present study investigated the cognitive and anatomical relationship between sentence comprehension and a nonsyntactic vWM task. We correlated general and type-specific sentence comprehension accuracy and DB scores with voxelwise gray matter volumes in a large group of patients with neurodegenerative diseases that differentially involve the language network. The results show that the dorsolateral portions of the left inferior and middle frontal gyri were largely shared between the DB task and comprehension of multiclausal sentences with embedded relative clauses. However, within this large area of common involvement, multiclausal sentences showed stronger association with the ventral region of the left inferior frontal gyrus, whereas DB was associated with greater atrophy in the left middle frontal gyrus. These data support the view of a distributed network of brain regions for sentence comprehension in which the left frontal region also mediates general, nonsyntactic vWM functions, with a modulation of this

sphere with different relative distributions (Gorno-Tempini et al., 2004). The analyses of CYCLE-R behavioral data showed that there was variability in the cognitive performance with no significant differences between subtypes of PPA and the other disorders (Table 1). The variability of anatomical as well as behavioral distribution is necessary for the implementation of a regression design. Despite all of these arguments, we nevertheless conducted an exploratory analysis in which progressive nonfluent aphasia, semantic dementia, and LPA were considered as nuisance variables. The main left frontal findings were still present at a cor- system depending on specific vWM demands. We discuss these findings with respect to previous neuroimaging and neuropsychological studies and consider their possible implication for current theoretical models of syntactic comprehension and working memory.

Overall accuracy in sentence comprehension, regardless of morphosyntactic structure, was associated with the left middle posterior superior temporal gyrus and inferior parietal lobule, a finding that is consistent with previous studies of sentence com- 
prehension (Just et al., 1996; Stromswold et al., 1996; Carpenter et al., 1999; Dapretto and Bookheimer, 1999; Ni et al., 2000; Friederici et al., 2003; Ben-Shachar et al., 2004; Wartenburger et al., 2004). In the present study, the left temporal area showed a correlation with overall sentence comprehension abilities, but not with nonsyntactic vWM abilities, supporting its specificity for sentence processing. However, because the middle and superior temporal gyri have been implicated previously in a variety of other language tasks (Caramazza and Zurif, 1976; Price, 2000; Binder and Price, 2001; Kaan and Swaab, 2002; Dronkers et al., 2004), their role in sentence processing most likely does not involve syntax per se but rather other aspects of lexical and semantic processing necessary for sentence comprehension.

When we considered correlations of accuracy in each type of sentence separately, we found that performance on multiclausal relatives with embedded clauses (type 3 ) correlated significantly with left middle and inferior frontal volumes, including pars triangularis of Broca's area (BA 45). Although theories vary (Caplan and Waters, 1999; Grodzinsky, 2000; MacDonald and Christiansen, 2002), most authors agree that patients with Broca's aphasia show impaired comprehension of complex sentences because they fail to establish long-distance dependencies between different sentence components (Caramazza and Zurif, 1976; Caplan et al., 1985, 1996; Zurif et al., 1993; Grodzinsky, 2000; Tettamanti et al., 2002). Consistently, previous research has suggested that Broca's area plays a role in the comprehension of sentences that require a greater vWM load (Just et al., 1996; Stromswold et al., 1996; Caplan et al., 1998, 2000; Caplan and Waters, 1999; Fiebach et al., 2001; Cooke et al., 2002).

There is still debate in the literature about whether the vWM resources necessary for comprehension of complex sentences are shared with other verbal tasks, or whether they are specific to sentence processing (Just and Carpenter, 1992; Just et al., 1996; Caplan and Waters, 1999). A large body of functional imaging evidence has shown involvement of the dorsolateral frontal cortex in the maintenance and manipulation of information with greater left lateralization for verbal material (Smith and Jonides, 1997; Smith et al., 1998; D’Esposito et al., 1999). In the current study, we found that DB scores correlated with dorsolateral prefrontal and left inferior parietal volumes. Most functional imaging studies that have considered working memory resources in syntactic processes have compared different sentence types with different working memory loads (simple versus complex sentences) (Just et al., 1996; Stromswold et al., 1996; Stowe et al., 1998; Caplan and Waters, 1999; Caplan et al., 2000; Keller et al., 2001; Cooke et al., 2002), but only a few have directly compared sentence processing that requires a high working memory load to tasks requiring maintenance and elaboration of nonsyntactic verbal material (Stowe et al., 1998; Kuperberg et al., 2003). Two of these studies found left frontal activity to be independent of the stimuli, supporting our result that syntactic and nonsyntactic working memory tasks largely share the same left frontal network (Stowe et al., 1998; Kuperberg et al., 2003). In particular, the inferior and middle frontal gyri might support the manipulation of temporal sequencing required for both the integration of multiclausal sentences (type 3 ) and the reverse ordering of a string of numbers (DB) (Gelfand and Bookheimer, 2003). However, our findings show that within this left dorsolateral frontal area, some regions show a greater effect for one of the two tasks. In particular, performance in multiclausal sentences showed greater correlation with pars triangularis of Broca's area. This area has been associated previously with the processing of wh-questions with greater working memory demands ("language-related working memory") and not with syntactic processing per se (Fiebach et al., 2001, 2005). Together, our results support the view that a single vWM system is involved in all linguistic tasks, as stated in the CC READER model (Just and Carpenter 1987). However, the greater correlation of multiclausal relatives in the pars triangularis and of DB in the left middle frontal gyrus, suggests that portions of this shared system can differently contribute to performance of each task. These data therefore suggests a reconciliation of the debate between the existence of one (Just and Carpenter, 1992) or multiple (Caplan and Waters, 1999) vWM systems.

Consistent with previous findings, accuracy was lower for comprehension of nonbasic (type 2 and 3) than basic sentences in our group of patients (Grossman et al., 1996; Gorno-Tempini et al., 2004; Grossman and Moore, 2005) However, there was no significant difference in accuracy between types 2 and 3, showing that the anatomical differences we observed cannot simply be explained by differences in "general difficulty." Although sentences with embedded relative clauses are consistently considered "complex" structures, the classification of passive structures is less clear. These sentences are "noncanonical" because of their atypical word order and can be difficult to understand for patients with Broca's aphasia. However, they do not consistently elicit left frontal activations in functional neuroimaging experiments when compared with active structures (Caplan, 2000; Ni et al., 2000; Wartenburger et al., 2004). Consistently, type 2 word order sentences (which included passives) only showed a trend for correlation with the same left frontal region that correlated significantly with type 3 multiclausal relatives. When directly compared, pars triangularis showed a greater effect for type 3 than type 2. Although our study did not aim at directly comparing the two types of sentences, our results suggest, as predicted by Caplan and Waters (1999), that multiclausal sentences might require higher vWM resources both at the cognitive and the anatomical levels.

The main limitations of this study are the known limitation of the VBM technique and the sentence comprehension task (CYCLE-R) that we used, which is a clinical test, not specifically designed for the experiment. The CYCLE-R was initially developed for children, but it has been successfully used to classify adult vascular aphasics (Dronkers et al., 2004). Most sentences in the CYCLE-R are semantically reversible and processes other than vMW, such as combinatorial semantics, might be involved in accurately understanding them. However, the VBM analyses controlled for accuracy in type 1 (simple reversible sentences) and partly discount this possibility. In addition, it might be possible that the type of task used (i.e., off-line task), more than sentence complexity, required high vWM demand (Cupples and Inglis, 1993; Rochon et al., 1994; Waters and Caplan, 1997). Finally, a possible confound is that the nonbasic sentences (type 2 and 3) were not matched for length, number of words, and stimulus duration. However, the nouns, verbs, and adjectives were high-frequency words, used repetitively across all sentence types, which could have helped in creating uniformity of the stimuli. Furthermore, a post hoc analysis using only sentences matched for length within each type yield the same result.

In conclusion, we found that vWM for syntactic and nonsyntactic materials are largely sustained by a common left frontal neural system, with some regions showing task-specific modulation. This result is in keeping with the notion of a large, distributed processing system for sentence comprehension that shares cognitive resources with other nonlinguistic tasks. 


\section{References}

Ashburner J, Friston KJ (2001) Why voxel-based morphometry should be used. NeuroImage 14:1238-1243.

Baddeley A, Hitch G (1974) Working memory. In: The psychology of learning and motivation (Bower GH, ed), pp 47-90. San Diego: Academic.

Ben-Shachar M, Palti D, Grodzinsky Y (2004) Neural correlates of syntactic movement: converging evidence from two fMRI experiments. NeuroImage 21:1320-1336.

Binder J, Price PC (2001) Functional neuroimaging of language. In: Handbook of functional neuroimaging of cognition (Cabeza R, Kingstone A, eds), pp 187-251: MIT.

Binder JR, Frost JA, Hammeke TA, Cox RW, Rao SM, Prieto T (1997) Human brain language areas identified by functional magnetic resonance imaging. J Neurosci 17:353-362.

Boeve BF, Lang AE, Litvan I (2003) Corticobasal degeneration and its relationship to progressive supranuclear palsy and frontotemporal dementia. Ann Neurol 54:S15-S19.

Bookstein FL (2001) "Voxel-based morphometry" should not be used with imperfectly registered images. NeuroImage 14:1454-1462.

Bottini G, Corcoran R, Sterzi R, Paulesu E, Schenone P, Scarpa P, Frackowiak RS, Frith CD (1994) The role of the right hemisphere in the interpretation of figurative aspects of language. A positron emission tomography activation study. Brain 117:1241-1253.

Brambati SM, Myers D, Wilson A, Rankin KP, Allison SC, Rosen HJ, Miller BL, Gorno-Tempini ML (2006) The anatomy of category-specific object naming in neurodegenerative diseases. J Cogn Neurosci 18:1644-1653.

Canavan AG, Passingham RE, Marsden CD, Quinn N, Wyke M, Polkey CE (1989) Sequence ability in parkinsonians, patients with frontal lobe lesions and patients who have undergone unilateral temporal lobectomies. Neuropsychologia 27:787-798.

Caplan D (2000) PET studies of syntactic processing. In: Language and the brain (Grodzinsky Y, Shapiro LP, Swinney D, eds). San Diego: Academic.

Caplan D, Waters GS (1999) Verbal working memory and sentence comprehension. Behav Brain Sci 22:77-94; discussion 95-126.

Caplan D, Baker C, Dehaut F (1985) Syntactic determinants of sentence comprehension in aphasia. Cognition 21:117-175.

Caplan D, Hildebrandt N, Makris N (1996) Location of lesions in stroke patients with deficits in syntactic processing in sentence comprehension. Brain 119:933-949.

Caplan D, Alpert N, Waters G (1998) Effects of syntactic structure and propositional number on patterns of regional cerebral blood flow. J Cogn Neurosci 10:541-552.

Caplan D, Alpert N, Waters G, Olivieri A (2000) Activation of Broca's area by syntactic processing under conditions of concurrent articulation. Hum Brain Mapp 9:65-71.

Caramazza A, Zurif EB (1976) Dissociation of algorithmic and heuristic processes in language comprehension: evidence from aphasia. Brain Lang 3:572-582.

Carpenter PA, Just MA, Keller TA, Eddy WF, Thulborn KR (1999) Time course of fMRI-activation in language and spatial networks during sentence comprehension. NeuroImage 10:216-224.

Cohen J (1988) Statistical power analysis for the behavioral sciences, Ed 2. Hillsdale, NJ: L. Erlbaum Associates.

Cooke A, Zurif EB, DeVita C, Alsop D, Koenig P, Detre J, Gee J, Pinango M, Balogh J, Grossman M (2002) Neural basis for sentence comprehension: grammatical and short-term memory components. Hum Brain Mapp 15:80-94.

Cooke A, Grossman M, Devita C, Gonzalez-Atavales J, Moore P, Chen W, Gee J, Detre J (2006) Large-scale neural network for sentence processing. Brain Lang 96:14-36.

Cupples L, Inglis A (1993) When tasks demands induce "asyntactic" comprehension: a study of sentence interpretation in aphasia. Cogn Neuropsychol 10:201-234.

Curtiss S, Yamada J (1988) Curtiss-Yamada Comprehensive Language Evaluation. Retrieved May 22, 2007, from http://thecycletest.com.

Dapretto M, Bookheimer SY (1999) Form and content: dissociating syntax and semantics in sentence comprehension. Neuron 24:427-432.

D’Esposito M, Postle BR, Ballard D, Lease J (1999) Maintenance versus manipulation of information held in working memory: an event-related fMRI study. Brain Cogn 41:66-86.

Dronkers NF, Wilkins DP, Van Valin Jr RD, Redfern BB, Jaeger JJ (2004)
Lesion analysis of the brain areas involved in language comprehension. Cognition 92:145-177.

Fiebach CJ, Schlesewsky M, Friederici AD (2001) Syntactic working memory and the establishment of filler-gap dependencies: insights from ERPs and fMRI. J Psycholinguist Res 30:321-338.

Fiebach CJ, Schlesewsky M, Lohmann G, von Cramon DY, Friederici AD (2005) Revisiting the role of Broca's area in sentence processing: syntactic integration versus syntactic working memory. Hum Brain Mapp 24:79-91.

Fiez JA, Raife EA, Balota DA, Schwarz JP, Raichle ME, Petersen SE (1996) A positron emission tomography study of the short-term maintenance of verbal information. J Neurosci 16:808-822.

Friederici AD, Meyer M, von Cramon DY (2000) Auditory language comprehension: an event-related fMRI study on the processing of syntactic and lexical information. Brain Lang 75:289-300.

Friederici AD, Ruschemeyer SA, Hahne A, Fiebach CJ (2003) The role of left inferior frontal and superior temporal cortex in sentence comprehension: localizing syntactic and semantic processes. Cereb Cortex 13:170-177.

Friston KJ, Holmes AP, Price CJ, Buchel C, Worsley KJ (1999) Multisubject fMRI studies and conjunction analyses. NeuroImage 10:385-396.

Friston KJ, Penny WD, Glaser DE (2005) Conjunction revisited. NeuroImage 25:661-667.

Gelfand JR, Bookheimer SY (2003) Dissociating neural mechanisms of temporal sequencing and processing phonemes. Neuron 38:831-842.

Genovese CR, Lazar NA, Nichols T (2002) Thresholding of statistical maps in functional neuroimaging using the false discovery rate. NeuroImage 15:870-878.

Good CD, Johnsrude IS, Ashburner J, Henson RNA, Friston KJ, Frackowiak RSJ (2001) A voxel-based morphometric study of ageing in 465 normal adult human brains. NeuroImage 14:21-36.

Good CD, Scahill RI, Fox NC, Ashburner J, Friston KJ, Chan D, Crum WR, Rossor MN, Frackowiak RS (2002) Automatic differentiation of anatomical patterns in the human brain: validation with studies of degenerative dementias. NeuroImage 17:29-46.

Gorno-Tempini ML, Dronkers NF, Rankin KP, Ogar JM, Phengrasamy L, Rosen HJ, Johnson JK, Weiner MW, Miller BL (2004) Cognition and anatomy in three variants of primary progressive aphasia. Ann Neurol 55:335-346.

GrodzinskyY (2000) The neurology of syntax: language use without Broca's area. Behav Brain Sci 23:1-21; discussion 21-71.

Grossman M, Moore P (2005) A longitudinal study of sentence comprehension difficulty in primary progressive aphasia. J Neurol Neurosurg Psychiatry 76:644-649.

Grossman M, D’Esposito M, Hughes E, Onishi K, Biassou N, White-Devine T, Robinson KM (1996) Language comprehension profiles in Alzheimer's disease, multi-infarct dementia, and frontotemporal degeneration. Neurology 47:183-189.

Just MA, Carpenter PA (1987) The psychology of reading and language comprehension. Newton, MA: Allyn \& Bacon.

Just MA, Carpenter PA (1992) A capacity theory of comprehension: individual differences in working memory. Psychol Rev 99:122-149.

Just MA, Carpenter PA, Keller TA, Eddy WF, Thulborn KR (1996) Brain activation modulated by sentence comprehension. Science 274:114-116.

Kaan E, Swaab TY (2002) The brain circuitry of syntactic comprehension. Trends Cogn Sci 6:350-356.

Keller TA, Carpenter PA, Just MA (2001) The neural bases of sentence comprehension: a fMRI examination of syntactic and lexical processing. Cereb Cortex 11:223-237.

Keller TA, Carpenter PA, Just MA (2003) Brain imaging of tongue-twister sentence comprehension: twisting the tongue and the brain. Brain Lang 84:189-203.

Kramer JH, Jurik J, Sha SJ, Rankin KP, Rosen HJ, Johnson JK, Miller BL (2003) Distinctive neuropsychological patterns in frontotemporal dementia, semantic dementia, and Alzheimer disease. Cogn Behav Neurol 16:211-218.

Kuperberg GR, Holcomb PJ, Sitnikova T, Greve D, Dale AM, Caplan D (2003) Distinct patterns of neural modulation during the processing of conceptual and syntactic anomalies. J Cogn Neurosci 15:272-293.

Litvan I, Agid Y, Calne D, Campbell G, Dubois B, Duvoisin RC, Goetz CG, Golbe LI, Grafman J, Growdon JH, Hallett M, Jankovic J, Quinn NP, Tolosa E, Zee DS (1996) Clinical research criteria for the diagnosis of progressive supranuclear palsy (Steele-Richardson-Olszewski syn- 
drome): report of the NINDS-SPSP international workshop. Neurology 47:1-9.

Litvan I, Campbell G, Mangone CA, Verny M, McKee A, Chaudhuri KR, Jellinger K, Pearce RKB, D’Olhaberriague L (1997) Which clinical features differentiate progressive supranuclear palsy (Steele-RichardsonOlzewski syndrome) form related disorders? Brain 120:65-74.

MacDonald MC, Christiansen MH (2002) Reassessing working memory: comment on Just and Carpenter (1992) and Waters and Caplan (1996). Psychol Rev 109:35-54; discussion 55-74.

Maldjian JA, Laurienti PJ, Kraft RA, Burdette JH (2003) An automated method for neuroanatomic and cytoarchitectonic atlas-based interrogation of fMRI data sets. NeuroImage 19:1233-1239.

McKeith IG, Galasko D, Kosaka K, Perry EK, Dickson DW, Hansen LA, Salmon DP, Lowe J, Mirra SS, Byrne EJ, Lennox G, Quinn NP, Edwardson JA, Ince PG, Bergeron C, Burns A, Miller BL, Lovestone S, Collerton D, Jansen EN, et al. (1996) Consensus guidelines for the clinical and pathologic diagnosis of dementia with Lewy bodies (DLB): report of the consortium on DLB international workshop. Neurology 47:1113-1124.

McKeith IG, Dickson DW, Lowe J, Emre M, O’Brien JT, Feldman H, Cummings J, Duda JE, Lippa C, Perry EK, Aarsland D, Arai H, Ballard CG, Boeve B, Burn DJ, Costa D, Del Ser T, Dubois B, Galasko D, Gauthier S, et al. (2005) Diagnosis and management of dementia with Lewy bodies: third report of the DLB Consortium. Neurology 65:1863-1872.

McKhann G, Drachman D, Folstein M, Katzman R, Price D, Stadlan EM (1984) Clinical diagnosis of Alzheimer's disease: report of the NINCDS-ADRDA Work Group under the auspices of Department of Health and Human Services Task Force on Alzheimer's disease. Neurology 34:939-944.

Mesulam MM (1987) Primary progressive aphasia-differentiation from Alzheimer's disease. Ann Neurol 22:533-534.

Neary D, Snowden JS, Gustafson L, Passant U, Stuss D, Black S, Freedman M, Kertesz A, Robert PH, Albert M, Boone K, Miller BL, Cummings J, Benson DF (1998) Frontotemporal lobar degeneration: a consensus on clinical diagnostic criteria. Neurology 51:1546-1554.

Ni W, Constable RT, Mencl WE, Pugh KR, Fulbright RK, Shaywitz SE, Shaywitz BA, Gore JC, Shankweiler D (2000) An event-related neuroimaging study distinguishing form and content in sentence processing. J Cogn Neurosci 12:120-133.
Paulesu E, Frith CD, Frackowiak RS (1993) The neural correlates of the verbal component of working memory. Nature 362:342-345.

Price CJ (2000) The anatomy of language: contributions from functional neuroimaging. J Anat 197:335-359.

Rochon E, Waters GS, Caplan D (1994) Sentence comprehension in patients with Alzheimer's disease. Brain Lang 46:329-349.

Rosen HJ, Allison SC, Schauer GF, Gorno-Tempini ML, Weiner MW, Miller BL (2005) Neuroanatomical correlates of behavioural disorders in dementia. Brain 128:2612-2625.

Smith EE, Jonides J (1997) Working memory: a view from neuroimaging. Cognit Psychol 33:5-42.

Smith EE, Jonides J, Marshuetz C, Koeppe RA (1998) Components of verbal working memory: evidence from neuroimaging. Proc Natl Acad Sci USA 95:876-882.

Stowe LA, Broere CA, Paans AM, Wijers AA, Mulder G, Vaalburg W, Zwarts F (1998) Localizing components of a complex task: sentence processing and working memory. NeuroReport 9:2995-2999.

Stromswold K, Caplan D, Alpert N, Rauch S (1996) Localization of syntactic comprehension by positron emission tomography. Brain Lang 52:452-473.

Tettamanti M, Alkadhi H, Moro A, Perani D, Kollias S, Weniger D (2002) Neural correlates for the acquisition of natural language syntax. NeuroImage 17:700-709.

Tzourio-Mazoyer N, Landeau B, Papathanassiou D, Crivello F, Etard O, Delcroix N, Mazoyer B, Joliot M (2002) Automated anatomical labeling of activations in SPM using a macroscopic anatomical parcellation of the MNI MRI single-subject brain. NeuroImage 15:273-289.

Wartenburger I, Heekeren HR, Burchert F, Heinemann S, De Bleser R, Villringer A (2004) Neural correlates of syntactic transformations. Hum Brain Mapp 22:72-81.

Waters GS, Caplan D (1997) Working memory and on-line sentence comprehension in patients with Alzheimer's disease. J Psycholinguist Res 26:377-400.

Wechsler DA (1997) Wechsler adult intelligence scale, Ed 3. San Antonio, TX: The Psychological Corporation.

Zurif E, Swinney D, Prather P, Solomon J, Bushell C (1993) An on-line analysis of syntactic processing in Broca's and Wernicke's aphasia. Brain Lang 45:448-464. 